\title{
Pastoral care with young people suffering from depression in the context of Soweto
}

\begin{tabular}{|c|c|}
\hline \multicolumn{2}{|c|}{$\begin{array}{l}\text { Authors: } \\
\text { Mwansa C. Kimpinde }{ }^{1} \\
\text { Yolanda Dreyer }\end{array}$} \\
\hline \multicolumn{2}{|c|}{$\begin{array}{l}\text { Affiliations: } \\
\text { }{ }^{1} \text { Faculty of Theology and } \\
\text { Religion, University of } \\
\text { Pretoria, Pretoria, } \\
\text { South Africa }\end{array}$} \\
\hline \multicolumn{2}{|c|}{$\begin{array}{l}\text { Research Project Registration: } \\
\text { Project Leader: Yolanda } \\
\text { Dreyer (1) } \\
\text { Project Number: } 2546930\end{array}$} \\
\hline \multicolumn{2}{|c|}{$\begin{array}{l}\text { Description: This research is } \\
\text { part of the project, 'Gender } \\
\text { Studies and Practical } \\
\text { Theology Theory Formation', } \\
\text { directed by Prof. Dr Yolanda } \\
\text { Dreyer, Department of } \\
\text { Practical Theology, Faculty of } \\
\text { Theology and Religion, } \\
\text { University of Pretoria. }\end{array}$} \\
\hline \multicolumn{2}{|c|}{$\begin{array}{l}\text { Corresponding author: } \\
\text { Yolanda Dreyer, } \\
\text { yolanda.dreyer@up.ac.za }\end{array}$} \\
\hline \multicolumn{2}{|c|}{$\begin{array}{l}\text { Dates: } \\
\text { Received: } 01 \text { July } 2020 \\
\text { Accepted: } 21 \text { Aug. } 2020 \\
\text { Published: } 10 \text { Nov. } 2020\end{array}$} \\
\hline \multicolumn{2}{|c|}{$\begin{array}{l}\text { How to cite this article: } \\
\text { Kimpinde, M.C. \& Dreyer, Y., } \\
\text { 2020, 'Pastoral care with } \\
\text { young people suffering from } \\
\text { depression in the context of } \\
\text { Soweto.', HTS Teologiese } \\
\text { Studies/Theological Studies } \\
76(3), \text { a6225. https://doi. } \\
\text { org/10.4102/hts.v76i3.6225 }\end{array}$} \\
\hline \multicolumn{2}{|c|}{$\begin{array}{l}\text { Copyright: } \\
\text { (c) 2020. The Authors. } \\
\text { Licensee: AOSIS. This work } \\
\text { is licensed under the } \\
\text { Creative Commons } \\
\text { Attribution License. }\end{array}$} \\
\hline \multicolumn{2}{|l|}{ Read online: } \\
\hline 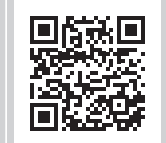 & $\begin{array}{l}\text { Scan this QR } \\
\text { code with your } \\
\text { smart phone or } \\
\text { mobile device } \\
\text { to read online. }\end{array}$ \\
\hline
\end{tabular}

The situation and challenges of young people with depression in the urban African context of Soweto, Johannesburg, South Africa, are investigated from a pastoral care perspective. Depression is one of the more prevalent mental disorders. In African contexts it is often equated with demon possession. The aim of this article is to investigate the interplay between Western understandings of depression and African perspectives, and to come to a deeper understanding of the way in which support and healing are approached in this context. The article investigates the ways in which young South Africans in Soweto, their families and faith communities cope with and understand 'depression' on the one hand, and the culturally related phenomenon of 'demon possession' on the other. The article proposes a collaborative method of providing support which requires the cooperation of psychologists, psychiatrists, social workers, African spiritual healers and pastoral caregivers.

Contribution: The article contributes to an understanding of the experience of depression among young people in a context where both Western psychological ideas and African cultural and religious beliefs with regard to demon possession, play a role. Professionals from the various relevant fields should collaborate in order to provide effective support.

Keywords: pastoral care; youth; depression; demonic possession; urban African context.

\section{Introduction}

The article proposes a pastoral care praxis, caring for young people in Soweto who suffer from depression or demon possession, depending on how their condition is diagnosed in medical terms, or designated in cultural terms. These two possible designations already indicate a clash of worldviews. Both worldviews can be found in their context. To provide adequate care for these young people, a holistic form of care should be found that effectively attends to the physical, psychological, social, cultural, mental and spiritual aspects of being human.

Depression is the most prevalent form of psychotic behaviour and is characterised by a 'breakdown of integrated personality function, withdrawal from reality, emotional blocking, distortion of thought and behaviour' (Mohanty 1984:221). It is disabling and one of the most widespread behavioural disorders, also referred to as 'mental illness'. According to Mojtabai, Olfson and Han (2016:48), depression is often accompanied by emotions such as a sense of loss, failure; a sense of injustice and ill health. Joy and sorrow, growth and decay, light and darkness are part of life and even the negative aspect of each of these pairs has a valid role to play in the greater scheme of things Assari et al. (2018:14). However, for those who are prone to depression it becomes increasingly difficult to sustain hope and to experience the positive side of life. Life's ordinary struggles can become unbearable. If an already negative period in a person's life is exacerbated by, for example, the emotional trauma of bereavement or severe financial loss, people can fear for their survival. The platitudes of well-meaning friends and loved ones do not alleviate their situation. They become increasingly convinced that no one understands what they are going through (Assari 2017:76). People who suffer from depression are not just 'feeling sorry for themselves'. According to the American Psychiatric Association in its Diagnostic and Statistical Manual of Mental Disorders (DSM-5 2013) depression, as a recognised medical condition with specific signs and symptoms. It is the fastest growing epidemic in the developed world, as indicated by the World Health Organization (WHO), which ranks depression at number five in its top ten list of disabling illnesses.

With the shift to modern and postmodern paradigms the idea of 'demonic possession' fell out of favour (Isaacs 2018:373). These ways of thinking have not presented answers to the phenomena 
associated with demonic possession, or developed appropriate methods of treatment for those who experience the signs and symptoms of classical possession. Though belief in possession is often rejected as 'superstition', the phenomena associated with demonic possessions do exist and must be dealt with. Crooks (2007:28, 45-76) defends the use of a traditional paradigm for understanding the phenomena associated with demonic possession. He suggests that demonic possession should be viewed as a valid phenomenon. He argues that denial, because of a shift in philosophical paradigms, does not negate the reality of an event. He does not find the recently adopted explanations of the natural sciences to be necessarily more convincing than traditional views. Using what he calls a 'post-anecdotal' method, Crooks (2007:45) shows that the ancient system of demonology is not only as adequate as the modern medical model, but more effectively describe the phenomena of possession states.

\section{The context}

Over a period of 5 years the following statistics from the Psychiatric and Psychological Department Annual Report of 2019 , indicate the prevalence of depression amongst patients in the Baragwanath Hospital in Soweto, Johannesburg. In 2014 there were 53 patients with depression out of 254, which is $36 \%$; in 2015 there were 26 patients with depression out of 139 patients, which is $18 \%$; in 2016 there were 12 patients with depression out of 74 patients, which is $19 \%$; in 2017 there were 16 patients with depression out of 77, which is $18 \%$; in 2018 there were six patients with depression out of 41 patients, which is $16 \%$. This record, however, represents only the small number of families who dared to visit medical professionals with the problem of a family member with depression. There are probably many more who gave up hope without fully understanding the mental health issue at hand. Often, families are not equipped to deal with the problem of depression. Domestic violence, poverty and other socio-economic factors exacerbate the problems associated with depression - both with regard to contributing to the causes of the young people's condition, and as an impediment to creating an optimal environment for their recovery.

Many people in this context have no in-depth knowledge of the classification and indicators of mental disorders. Some may have superficial knowledge of depression because they know people who suffer with it, or have heard of the condition. Many do not want to associate with individuals with depression for fear of stigmatisation. The slightest indication of a 'tainted family lineage' would mean social rejection in that community. This would, for example, affect marriage alliances between families and would in general impede social interaction.

Those who are somewhat familiar with the term 'depression', often have a wide range of understanding of what it entails. Some see it as a 'split personality', others as a 'curse'.
Some see it as 'mental illness', whereas others do not know what this term signifies. Many are aware of the prevalence of depression amongst young people in Soweto, but even clinicians acknowledged in interviews that they sometimes fail to recognise the symptoms of depression in the initial stages. Generally, people in the Soweto context are not well equipped to deal with the reality of mental illness, including depression.

In African contexts, mental disorders are often perceived as demonic possession, in other words as the result of some supernatural influence. Where a community places a strong emphasis on supernatural powers, it would be difficult to identify depression and provide people with the necessary help. In the context of Soweto, a variety of professionals are involved with matters of healing and fullness of life. These include psychiatrists, psychologists, social workers, pastors and traditional healers. The question is how these healers and caregivers can cooperate to provide effective holistic care to young people with depression in Soweto.

People with an African worldview depart from the cultural assumption that those who are 'demon possessed', or victims of witchcraft should be treated by a traditional healer. They could consult a prayer warrior, an exorcist, or can be taken by their family to a prayer home. Wiebe (2011:156-178) points out that symptoms of depression are often attributed to either demon possession or witchcraft. Individuals who start behaving strangely can be suspected of either. In such a cultural context it is rarely suggested that a medical doctor should be consulted. One of the recommended treatments would be for them to consult a prayer warrior. Another is to consult a sangoma who would perform rituals and incantations. The fees of such practitioners are rather high. Other 'treatments can include whipping with tree branches' (Halloy \& Naumescu 2012:77).

Clinical depression often sets in during early adulthood. In African contexts this is, at times, misdiagnosed as demon possession, or being bewitched. Relatives do what they can to help the sufferer. They take them to prayer warriors, sangomas or prayer homes, but as time passes without any signs of improvement, they lose hope and accept the malady as part of their life. However, not all people who are suspected of being possessed are in fact possessed. So also, not all people who are suspected of being victims of a curse, are suffering because of that (Mercer 2013:16). Demon possession is a common cultural and spiritual explanation for the psychological and biological condition of depression. This misconception then results in people not receiving the treatment they need. It is like when people are misdiagnosed and receive the wrong treatment in the medical world. Collaborative care which includes expertise from the various fields - medical, psychological, psychiatric, social work, pastoral and traditional-cultural - can contribute to avoiding misconceptions that can adversely affect the condition and life of persons who suffer and get them the treatment they need. 


\section{Multicultural pastoral care and liberation \\ African psychology}

The emerging field of African psychology is an important resource for an Africa-based, intercultural, pastoral theology and practice. In the contemporary context of Soweto, the ministry of pastoral care to young people who suffer from depression often do not yet utilise the useful theoretical perspectives and insights from this discipline. Although it is new and still evolving, it is increasingly making its presence felt in the broader area of African culture and religion (Awuah-Nyameke 2012:14). For the last two decades, African theologians have been pointing to the need for an in-depth focus on psychology and Africa. They have identified that strategies are needed to address the specific psychological problems and challenges of this cultural context with its tumultuous history.

From the perspective of African psychology, it is clear that a diverse range of psychological challenges face young people in Soweto who suffer from depression. Many of these are the direct result of the internalisation of oppressive messages and cultural behaviours regarding their condition (see Makhubela 2016:7). Psychological problems include low selfesteem, self-blame and internal conflict. On the cultural front they are burdened by misunderstandings about what depression is and how it manifests. They are often labelled and socially ostracised.

Unlike many current psychological theories that tend to see the source of the problem inside the person, as is discussed by feminist theologian and clinician, Christie Cozad Neuger (2001:22), both feminist pastoral care and African psychology (Wasike 2006:18) have shown that the source of the problem is more often than not the oppressive structures of the prevalent system and its definitions of depression. The psychological problems that young African people experience are not 'a disability' or 'a personality deficiency' but are often survival adaptations, or harmful adjustments to prevailing unhealthy systems. They are generally not given room to understand and accommodate African cultural perspectives and African psychology, and embrace the alternative perspectives of traditional beliefs that can provide them with a different orientation.

\section{Liberation psychology}

Although the idea of 'liberation' was adopted in a variety of fields, including theology, during the latter part of the 20th century, liberation psychology was conceived primarily by Ignacio Martín-Baró (1994:27), who was a priest as well as a trained social psychologist (eds. Montero \& Sonn 2009:3). He formulated his ideas in an article titled, 'Towards a psychology of liberation in the Bulletin of Psychology published by the Central American University in 1986. The article argues for the construction of a new transformative psychological practice for oppressed peoples (eds. Montero \& Sonn 2009:3). Martín-Baró (1994:27) outlined three basic tenets of liberation psychology, namely, a new goal, a new epistemology and a new praxis.

The most valuable goal of psychology, according to MartínBaró (1994:29), is to focus its theoretical and practical energies on the 'needs and sufferings of the majorities who are numbed by oppressive life circumstances' (Martin-Baró 1994:28). He argues that there is a link between an individual person's psychological problems and the wider social, political and economic contexts in which, the person's life is embedded. He intends for psychology to gain clarity in understanding the relationship between psychic and social structures, ideologies and discourses that force people into 'marginalised dependency' and 'oppressive misery' by taking away their ability to define their own lives. Fragmentation and apathy reduce people to a state of submission and they no longer expect anything from life (Lester 2003:94). Liberation psychology is amenable to the communal, contextual and intercultural model of pastoral care that should be developed for African communities in general, and that will be of use with regard to the psychological struggles of young people who suffer from depression. Such an approach attends to people's historical, cultural and social realities.

For Martín-Baró (1994:27) the goals of liberation psychology include that oppressed people should gain knowledge and understanding of what may not yet be present in their current state of oppression, but will be present in the tomorrow of their liberty. Truth is not to be found, but made (Martín-Baró 1994:28). Truth is constructed, not as:

$[A]$ matter of thinking for them or bringing them our ideas or solving their problems for them; it has to do with thinking and theorizing with them and for them. (Martín-Baró 1994:28)

The communal, contextual and intercultural model of pastoral care that this article envisages has a similar goal. Oppressed people are subjects of history rather than mere objects of either history or pastoral care. Conventional models of pastoral care tended to not take oppressed peoples' perspectives or experiences sufficiently seriously when devising pastoral care practices. This then deprives people of the subject status they deserve as human beings.

In his quest to develop a new epistemology, Martín-Baró was influenced by Paulo Freire's (2000) Pedagogy of the oppressed. Freire refers to 'pedagogy of the oppressed' and not for the oppressed - language that maintains their subject status. Ideas from liberation theology are evident. Liberation theology emphasises that the God of Jesus is to be found from the perspective of the poor. In the same vein a psychology of liberation teaches that from the oppressed existential truth can be discovered and built upon (Payne 2006:19). Martin-Baró (1994:29) proposes that existing knowledge be revised from the perspective of the poor and the oppressed. 
Martín-Baró (1994:3) challenges psychology to a new praxis: 'to place itself within the process alongside the dominated rather than alongside the dominator'. If such a new praxis that transforms people and reality is not developed, it will hamper the construction of a liberative psychological practice (Nylund \& Nylund 2003:388). Psychologists should then take a stand for the oppressed people and make ethical choices. However, the call to 'take sides' can, for psychologists, social workers or clergy, create an unhealthy and harmful 'us or them' dynamic which will not contribute positively to the transformation of communities. Further, such a paradigm also has the potential to replicate the strategies of the dominant and not succeed in breaking the cycle of domination (Payne 2006:19). There is a need to rather, work in an integrative and dialogical manner.

\section{Psychology, Christianity and traditional cultures}

Despite the tremendous technological and material advancements, there are still areas where people are completely cut off from the rest of the world. They still practise traditional ways of living and surviving. Prior to development of modern medicine, treatment for the sick and suffering were often rather harsh (Lagacé-Seguin \& d'Entremont 2010:37), especially the treatment of the mentally ill because 'there were no effective methods for controlling their actions or helping them find relief from their inner torment' (Collins 2007:648). Some of the more popular treatment practises for the mentally ill was that they were 'whipped, starved, chained, seared with hot irons, dunked into freezing water' (Collins 2007:648). Such actions were justified on the basis that the patients were demon possessed and the torture would make their body uninhabitable to the demon(s). Another method was to make holes in the patient's scull to let the tormented spirits out. This was done without anaesthetics. Religious practitioners stood by as these methods were executed and exorcisms were done, 'especially in treating disorders that had a strong physiological basis' (Collins 2007:648).

Though psychology, Christianity and traditional beliefs and practices are discussed together in this article, they represent quite different approaches. Psychology, like any scientific enterprise, consists of theories that are embedded in a scientific worldview and emanate in detailed findings (Watts 2002:74-75). Within each field there is also a variety of sometimes rather divergent approaches. In psychology there are, for instance, both a more introspective and a more behaviourist method. According to Watts (2002:75-76), it is 'the more philosophical end of theology that intersects with scientific disciplines such as psychology'.

In the Old Testament, there are references to Moses and the other prophets repeatedly warning against activities such as divination, sorcery and idol worship (Virkler 1988:281). Similarly, in the New Testament demons are regarded as personal, fallen, spiritual beings that are stronger than human beings, but weaker than God. They were capable of oppressing and possessing human beings (Virkler 1988:281). To distinguish between demon possession and other mental illnesses, some characteristics were identified by Meier et al. (2010:260). Demon possessed people have more physical strength than other people. Demon possessed people respond differently when the name of Jesus is spoken to people with psychological problems. There is a change of voice when the demon speaks. Demon possessed people can perform supernatural acts. People who are demon possessed speak rationally whereas individuals with psychological problems do not. Those who are possessed often have a history of occult activities such as participating in séances or Satan worship. Demon possessed individuals do not respond to therapy (Meier et al. 2010:260).

Oesterreich (1930:54-56) also identifies characteristic features of demon possession. For him, most striking characteristic features of demon possession is the change in the persons' personality. They seem invaded and governed by a strange new soul. The second characteristic is their change in voice. The normal tone of the parent body is suppressed and transformed into a deep and heavy bass tone. The third characteristic feature is that the new voice does not speak according to the spirit of the normal personality but that of the new one.

New Testament authors discredited physical and mental illnesses because of demon possession (Virkler 1988: 281-282). They distinguished between the state of being demon possessed and other illnesses. They also distinguish between 'demonically caused and non-demonically caused illness in their discussion of healing' (Virkler 1988:282). Both categories of people were healed unconditionally, but the mode of healing was different. The former was healed by casting out the demons out of the possessed, whereas the latter was healed by other means. However, it is often difficult to distinguish between whether a person is demon possessed or mentally ill, because the 'symptoms arising from psychopathology and demonization overlap to a considerable extent' (Virkler 1988:285). Alhough there was no knowledge of mental disorders and treatments known today, the Bible does provide insight into human nature, showing the human condition before God. It provides an understanding of human suffering and offers hope (Collins 2007:635).

\section{Pastoral care perspectives}

Although 'depression' is understood differently in different cultures and ethnic groups, the condition is to be found in all walks of life (Davis \& Epkins 2009:29). The condition can, however, be exacerbated by a difficult environment. Living with depression can be even more difficult for people who bear the emotional scars of a traumatic youth. It is the task of pastoral caregivers to provide effective care for all the individuals and communities they serve (Mojtabai et al. 2016:25). The aim is to guide people who suffer with depression to live their life with human dignity and regain 
their confidence. Caregivers who journey with the young people who suffer from depression that is often equated to demonic possession in their culture should do so with respect and compassion. Kaplan and Benjamin (1991) describe the complexity of the work as follows:

$[T]$ he arena of pastoral work is multifaceted and full of surprises, unexpected problems and opportunities for profound insight into the human situation. It is an arena within which the pastor is privileged to be with people where they live and breathe, succeed and fail, relate intimately and experience alienation; it is the down-to-earth world of the human living. (p. 11)

Pastoral caregivers aim to provide guidance, support and encouragement to people in distress and to do so in a way that is liberating (Cobb, Kor \& Miller 2015). Another challenge is to create a safe environment and foster a healthy and healing relationship. Healed people can contribute further to the healing and transformation of society (Kaplan \& Benjamin 1991:11). The caregiver's focus is on the empowerment of the person bringing the voiceless to voice and, if necessary, becoming the voice of the voiceless and their prophet to the powerful. The pastoral care method proposed in this article has the aim to empower young people who suffer from depression so that they can regain their dignity and develop confidence in themselves. The faith community should be a space that nurtures the growth and development of its members. It should challenge negative constructs, which have a life-limiting effect on people, and affirm positive and constructive perspectives. A pastor provides not only care but is also called to be a prophetic witness in culture and society when the need arises.

\section{A new framework for a pastoral care praxis}

Pastoral care models that were developed in a Western context are often at a loss when it comes to the connection that is made in some cultures between the internal and external conditions of depression, and demonic possession (Matsaneng 2010:53-64). Often pastors do not have an adequate understanding of the condition of depression. Conventional pastoral care models generally focus on care and fail to include the two other critical needs of liberation and belonging (Gerkin 1997:70). The personal problems of the young people who suffer from depression and their families should be understood in the larger socio-cultural context. Both the internal and the external source of the depression should be addressed for the liberation and emancipation to be achieved.

Communal resources of faith communities should be utilised to serve the needs of the young people with depression and their families. Mbiti (1990:56) points out that cultural resources should be valued and affirmed. Through cultureaffirming practices from a liberation psychology perspective and intentional conscientisation, sufferers, their families and communities can gain insight into harmful ideologies and discourses they have internalised, and which have served to keep the young people who suffer to remain silent. Through conscientisation the young people can find solidarity in their communities and work towards the transformation of their social order to make it just and equal for all individuals and communities to exist in life-affirming ways.

To achieve a liberating African pastoral care praxis, a narrative approach which makes use of the pastoral care methods of positive deconstruction (Pollard 1997:44) and reframing (Capps 1990:126), can be effective strategies for identifying, deconstructing and reframing dominant cultural narratives. For pastoral caregivers in Soweto, the church need not only be the object of their pastoral ministry but can also be their partner in pastoral ministry. The young people themselves should be mobilised to resist the forces of oppression, and work towards their own liberation. However, one of the most debilitating effects of the current situation is that the community is divided. They do not form a cohesive force to resist the oppression to which they have been subjected. The internal division sabotages efforts to raise their concerns with a unified voice in the public arena.

Pastoral caregivers in Soweto can utilise the cultural capital represented by the young people and their families. For that, the church will have to develop and articulate a clear theological understanding of the relationship between the gospel and culture (Wasike 2006:12). Pastors can identify ways in which African cultural wisdom can be reclaimed and affirmed to become a medium through which the gospel message can be communicated effectively and experienced authentically (Cobb et al. 2015:69). The liberating and nourishing elements of the African culture can be utilised to meet the socio-cultural needs of the young people of Soweto. Another important strategy of pastoral ministry can be to collaborate with the authorities and with other religious movements, organisations and bodies, to address the many needs for care in the context of Soweto. Collaboration is essential if the needs of young people who suffer from depression are to be met.

\section{Creating a caring environment of trust}

As a pastoral caregiver in the context of Soweto, I found it a challenge to gain the trust of the young people. They were wary, not knowing what to expect. The challenge is to create trust, a 'firm belief in the reliability, truth, ability, or strength of someone or something' (Oxford Dictionary 2001:901) in order to be able 'to put one's confidence in a person or thing' (Goyal et al. 2014). Trust is needed for them to share their stories openly without fear of suspicion and stigma.

The distrust of the young people also extends to the faith community and the local community. People who suffer from depression, or have had experiences that are called demonic possession by others, do not feel safe to share their stories in the congregation for fear of being discriminated against, victimised and stigmatised. This exacerbates and perpetuates 
their suffering (Mercer 2013:17). The church should intentionally create an environment of trust where people can express their pain and struggles without fear of victimisation, discrimination and stigmatisation. To create such an environment, those in leadership will have to act with integrity when dealing with confidential matters. Empathetic care and a God-honouring, Christ-like disposition of the leaders can contribute to creating an environment of trust in the church (Mogoba 2011:170). Caregivers' own lives should display the kind of character that is worth imitating by the rest of the community. For a faith community and community to be trustworthy and able to create a safe environment for people who suffer with depression, education and awareness are needed.

\section{Education and conscientisation}

Depression amongst the young people in Soweto affects not only themselves, but also their families, the broader community and the faith community in which they worship (Masoga 2005:98). Education is necessary if every member, also people who suffer from depression or those who are suspected of demon possession, is to be fully accepted and treated with love and care (Cotton et al. 2006:17). Some examples are workshops, sermons and a teaching series, Bible study sessions, liturgies and songs/hymns that are appropriate for the purpose (Johnson 2010:79). Educational programmes should be implemented with sensitivity. Information should be accurate and presented in a professional way. An attitude of love and compassion and a deep concern for the human rights and dignity of all people is needed. Educators should challenge those who act in hurtful ways towards people who suffer, affirm and support those who are derided, and persuade a lifestyle change in all people (Koole et al. 2010:53). They should examine conditions that promote hurtful behaviour and advocate for Christian values that call for behavioural change. Other crucial matters include gender and the empowerment of young people. The Church is called to examine critically 'some of the cultural, customary and sexist practices that have been perpetuated in certain circles of society' (Koole et al. 2010:54). Failure to do this would continue to render depressed young people vulnerable to their circumstances and in conflict with their families and surroundings.

The faith community in its prophetic ministry should communicate a clear message that young people who suffer from depression should not be rejected, stigmatised, labelled and discriminated against in any way by fellow believers (Walker et al. 2014:105). The gospel's message of love, care, acceptance, grace and compassion should be brought to those who live with depression, or demonic possession. Through education, the whole body of Christ is challenged to examine itself from a deep reflection on, and understanding of, how people are affected by depression, and the positive or negative role that families and the community can play.

Conscientisation can be achieved by means of sharing testimonies. The stories of those who have found a way to live with their condition can give hope to those who are still struggling (Goldston et al. 2008:38). Those who have the courage, their testimonies can recoup a sense of strength, confidence and dignity in themselves. They can be empowered to go out and face their challenges with courage, knowing and feeling that they are supported by the community. In these testimonies there should also be space for lament regarding their experience of pain and trauma. Wimberley (2003:162) calls lament, the expression of the moans of the soul that arise from life's struggles and losses. Lament is brought to speech in prayer. Liturgies can be designed for the benefit of those who suffer and find it difficult to speak. This gives them the opportunity to express their pain openly in worship.

Education and creating awareness are about more than just teaching people about depression. It challenges the whole faith community to stand in solidarity before God, crying out for God's help and liberation. It would also involve the training and empowerment of pastoral caregivers to provide effective guidance for young people who suffer from depression.

\section{Destigmatisation}

Stigma can be described as 'a mark or sign of disgrace' (Oxford Dictionary 2001:824). It is a sign of social unacceptability associated with a deep sense of shame. If communities and faith communities attach stigma to certain conditions and actions, those who suffer will not be able to come forward and share their stories and experiences for fear of being judged, rejected and discriminated against. Until stigma is eradicated, it will remain difficult for young people with depression to experience a sense of belonging and the acceptance they so desperately need from their faith community and the broader community.

Destigmatisation would be to stop shaming and shunning people and to begin to treating them with dignity, love and compassion. Then they can feel fully human as people created in the image and likeness of God. They can then know and accept themselves as persons of worth and dignity, equal to all others in the community. This will communicate to them the strong message that they are still God's own beloved children, who need not be ashamed of themselves because of a condition over which they have no control. Destigmatisation will convey to the sufferers that the message of the gospel is communicated in a manner that brings about healing and transformation.

\section{Support}

Faith communities can begin support groups where people with experience of depression can come together to share their stories and encourage one another. Such groups can also be spaces where people whose behaviour is detrimental to those who suffer, are challenged to change their behaviour. This would give them the opportunity to make right where they harmed others through their actions. Support groups for 
young people who suffer with depression and their families have the following aims:

$[T]$ o transform individuals into a real personal relationship with Jesus Christ through the baptism of the Spirit; to heal relationships and to build community - especially in the family and the neighbourhood community and, to transform society by healing relationships of injustice and oppression. (Goldston et al. 2008)

Every local church in Soweto can be a centre of healing and support if it takes seriously its mission to those who suffer, including young people who suffer from depression who live in their communities and worship in their churches. Christian believers are called to proclaim the gospel of Jesus Christ for healing and transformation (Pollard 1997:43).

The lack of support structures is, however, a problem throughout Africa. Pastors often feel ill-equipped to deal with the trauma that affects their congregants. Masoga (2005:239) suggests that professional counselling centres be established with the aim to provide care for the clergy. Waruta and Kinoti (eds. 2005:230) emphasise that clergy care should pay specific attention to their personality and ministry. Such centres should be places of healing, restoration and transformation.

\section{Welfare, advocacy and collaboration}

Faith communities have the mission to be a visible sign of Christ's presence in the world. According to Wasike (2006:35), the vitality of the Church depends to an extent on the health and integral well-being of the society and culture in which it operates. Therefore, it is the Church's salvific mission to promote and foster, healthy and healing human relationships at a public level (eds. Waruta \& Kinoti 2005:133). This means that the Church can and should partner with all other organisations that seek to advance the cause of those who suffer from depression. The Church must be the voice of the voiceless and the conscience of society. Its responsibility is to care for all who suffer. This includes young people who struggle with depression. Ministries can be developed with this group of people in mind.

Churches can establish recovery centres and partner with organisations that provide aid for those who suffer from depression. Together they can hold accountable those who do not live up to their mandate to deliver acceptable services to people who desperately need them. The body of Christ should follow his example: He challenged the causes of detrimental conditions in society. The Church's responsibility: that of loving liberation rather than judgement (eds. Waruta \& Kinoti 2005:133). Churches should be at the forefront of addressing the issue of depression with families and communities in order to fulfil its mandate to preach good news to the poor, proclaiming freedom to the captives, recovery of sight to the blind, releasing the oppressed and proclaiming the year of the Lord's favour (Lk 4:18-19).

\section{Collaborative support}

In general, depression is an often-misunderstood mental health condition in African cultures and contexts. From a pastoral perspective, a contribution can be made on various levels to improve the situation of the sufferers. The focus of this article was specifically on young people in the urban African context of Soweto. The contribution of pastoral caregivers can be to create awareness of the suffering of people with depression and the care they need from their support systems and communities. Another function, pastoral caregiver can fulfil is to educate both, the faith community and the broader community with regard to depression to foster a greater understanding of the realities and challenges of this particular mental health condition. With greater understanding harmful reactions and practices can be eliminated to a great extent. In African contexts specifically, where the condition of depression is often equated with demon possession, pastoral caregivers can also initiate and sustain cooperation amongst themselves and medical professionals, social workers and traditional healers to approach the problem holistically. The aim is that all the helping professions and the communities should work together to help and support young people who suffer, rather than foster misunderstandings of the condition and foment discord amongst the caregivers and support systems, exacerbating their suffering. The aim of the article was therefore to develop a contextual and collaborative pastoral care approach to depression amongst young people who suffer from depression, which takes seriously the interplay between Western understandings of depression and African perspectives in order to provide effective and holistic care and support.

\section{Acknowledgements Competing interests}

The authors have declared that no competing interest exist.

\section{Authors' contributions}

All authors contributed equally to this work.

\section{Ethical consideration}

This article followed all ethical standards for a research without direct contact with human or animal subjects.'

\section{Funding information}

This research received no specific grant.

\section{Data availability statement}

Data sharing is not applicable.

\section{Disclaimer}

The views and opinions expressed in this article are those of the authors and do not necessarily reflect the official policy or position of any affiliated agency of the authors. 


\section{References}

American Psychiatric Association, 2013, Diagnostic and statistical manual of mental disorders, 5th edn., American Psychiatric Association, Arlington, VA.

Assari, S., 2017, 'Combined racial and gender differences in the long-term predictive role of education on depressive symptoms and chronic medical conditions' Journal of Racial and Ethnic Health Disparities 4(3), 385-396. https://doi org/10.1007/s40615-016-0239-7

Assari, S., Preiser, B., Lankarani, M.M. \& Caldwell, C.H., 2018, 'Subjective socioeconomic status moderates the association between discrimination and depression in African American youth', Brain Sciences 8(4), 71. https://doi org/10.3390/brainsci8040071

Awuah-Nyameke, S., 2012, 'Religion and development: African traditional religion perspective', Journal Religious Studies and Theology 31(1), 75-90. https://doi. org/10.1558/rsth.v31i1.75

Capps, D., 1990, Reframing: A new method in pastoral care, Fortress, Minneapolis, MN.

Cobb, E., Kor, A. \& Miller, L, 2015, 'Support for adolescent spirituality: Contributions of religious practice and trait mindfulness', Journal of Religion and Health 54(3), 862-870. https://doi.org/10.1007/s10943-015-0046-1

Collins, G.R., 2007, Christian counselling: A comprehensive guide, Thomas Nelson, Nashville, TN.

Cotton, S., Zebracki, K., Rosenthal, S.L., Tsevat, J. \& Drotar, D., 2006, 'Religion/ spirituality and adolescent health outcomes: A review', Journal of Adolescent Health 38(4), 472-480. https://doi.org/10.1016/j.jadohealth.2005.10.005

Crooks, M, 2007, 'On the psychology of demon possession: The occult personality', The Journal of Mind and Behaviour 39(4), 373-384.

Davis, K.A. \& Epkins, C.C., 2009, 'Do private religious practices moderate the relation between family conflict and preadolescents' depression and anxiety symptoms?', The Journal of Early Adolescence 29(5), 693-717. https://doi.org/10.1177/ 0272431608325503

Freire, P., 2000, Pedagogy of the oppressed, Continuum, New York, NY.

Gerkin, C.V., 1997, An introduction to pastoral care, Abingdon, Nashville, TN.

Goldston, D.B., Molock, S.D., Whitbeck, L.B., Murakami, J.L., Zayas, L.H. \& Hall, G.C.N., 2008, 'Cultural considerations in adolescent suicide prevention and psychosocial treatment', American Psychologist 63(1), 14-31. https://doi.org/10.1037/0003 066X.63.1.14

Goyal, M., Singh, S., Sibinga, E.M., Gould, N.F., Rowland-Seymour, A., Sharma, R. et al., 2014, 'Meditation programs for psychological stress and well-being: A systematic review and meta-analysis', JAMA Internal Medicine 174(3), 357-368. https://doi. org/10.1001/jamainternmed.2013.13018

Halloy, A. \& Naumescu, V., 2012, 'Learning spirit possession: An introduction', Ethnos 77(2), 155-176. https://doi.org/10.1080/00141844.2011.618271

Isaacs, T.C., 2018, 'Demon possession: Symbolic language and the psychic fact', The Journal of Mind and Behaviour 39(4), 373-384.

Johnson, E.L., 2010, Psychology and Christianity: Five views, Inter Varsity Press Academic, Downers Grove, IL.

Kaplan, H.I. \& Benjamin, J.S., 1991, Synopsis of psychiatry: Behavioural sciences clinical psychiatry, Williams \& Wilkins, Baltimore, MD

Koole, S.L., McCullough, M.E., Kuhl, J. \& Roelofsma, P.H., 2010, 'Why religion's burdens are light: From religiosity to implicit self-regulation', Personality and Socia Psychology Review 14(1), 95-107. https://doi.org/10.1177/1088868309351109

Lagacé-Séguin, D.G. \& d'Entremont, M.L., 2010, 'A scientific exploration of positive psychology in adolescence: The role of hope as a buffer against the influences of psychosocial negativities', International Journal of Adolescence and Youth 16(1) 69-95. https://doi.org/10.1080/02673843.2010.9748046
Lester, A.D., 2003, The angry Christian, Westminster John Knox, London.

Makhubela, M., 2016, "“From psychology in Africa to African psychology": Going nowhere slowly', Journal of Psychology in Society 52, 1-18. https://doi. org/10.17159/2309-8708/2016/n52a1

Martín-Baró, I., 1994, Writings for a liberation psychology, Harvard University Press, Cambridge, MA.

Masoga, M., 2005, 'South African research in indigenous knowledge systems and challenges of change', Indilinga African Journal of Indigenous Knowledge System $4(1), 15-30$.

Matsaneng, P., 2010, 'Spiritual direction in Africa: A need for a different approach', The Way 49(3), 53-64.

Mbiti, J.S., 1990, African religions and philosophy, Heinemann Educational Books, Portsmouth, $\mathrm{NH}$

Meier, P.D., Minirth, F.B., Wichern, F.B. \& Ratcliff, D.E., 2010, Introduction to psychology and counselling: Christian perspectives and applications, Baker Academic, Grand Rapids, Ml.

Mercer, J., 2013, 'Deliverance, demonic possession, and mental illness: Some considerations for mental health professionals', Mental Health, Religion \& Culture 16(6), 595-611. https://doi.org/10.1080/13674676.2012.706272

Mogoba, M.S., 2011, 'The religious background to African Christianity: African Traditional Religion', in I. Mekoa (ed.), The journey of hope: Essays in honour of Dr Mmutlanyane Stanley Mogoba, pp. 170-185, Incwadi Press, Cape Town.

Mohanty, G., 1984, A textbook of Abnormal Psychology, Kalyani Publishers, Ludhiana.

Mojtabai, R., Olfson, M. \& Han, B., 2016, 'National trends in the prevalence and treatment of depression in adolescents and young adults', Paediatrics 138(6), 1-12. https://doi.org/10.1542/peds.2016-1878

Montero, M. \& Sonn, C.C. (eds.), 2009, 'About liberation and psychology: An introduction', Psychology of liberation: Theory and application, pp. 1-10, Springer, New York, NY.

Neuger, C.C., 2001, Counselling women: A narrative pastoral approach, Fortress, Minneapolis, MN.

Nylund, D. \& Nylund, D.A., 2003, 'Narrative therapy as a counter-hegemonic practice', Menand Masculinities 5(4),386-394. https://doi.org/10.1177/1097184X03251086

Oesterreich, T.K., 1930, Possession: Demoniacal and other, Kegan Paul, London.

Oxford Dictionary, 2001, Oxford University Press, Oxford.

Payne, M., 2006, Narrative therapy: An introduction to counsellors, Sage, London.

Pollard, N., 1997, Evangelism made slightly less difficult: How to interest people who are not interested, InterVarsity Press, Downers Grove, IL.

Virkler, H.A., 1988, Psychology and religion: Demon influence and psychopathology, Baker Book House, Grand Rapids, MI.

Walker, R.L., Salami, T.K., Carter, S.E. \& Flowers, K., 2014, 'Perceived racism and suicide ideation: Mediating role of depression but moderating role of religiosity among African American adults', Suicide and Life-Threatening Behaviour 44(5), 548-559. https://doi.org/10.1111/sltb.12089

Waruta, D.W. \& Kinoti, H.W. (eds.), 2005, Pastoral care in African Christianity, Action Publishers, Nairobi.

Wasike, A.N., 2006, Christianity and the African rituals of birth and naming, Initiatives, Nairobi.

Watts, F., 2002, Theology and psychology, Routledge, London.

Wiebe, P.H., 2011, 'Deliverance and exorcism in philosophical perspective', in W.K. Kay \& R. Parry (eds.), Exorcism and deliverance: Multidisciplinary studies, pp. 156-178, Paternoster, Milton Keynes.

Wimberley, E., 2003, Claiming God reclaiming dignity, Abingdon, Nashville, TN.

World Health Organisation, 2005, Child and adolescent mental health policies and plans: Mental health policy and service guidance package. Geneva: World Health Organisation. 